\title{
Pain Management after Surgery
}

\section{Shahverdi $\mathrm{E}^{1,2^{*}}$ and Khani $\mathrm{MA}^{3}$}

${ }^{1}$ Blood transfusion Research Center, High Institute for research and Education in Transfusion Medicine, Tehran, Iran

${ }^{2}$ Student Research Committee, Baqiyatallah University of Medical Sciences, Tehran, Iran

${ }^{3}$ Department of Medicine, Najafabad Branch, Islamic Azad University, Najafabad, Iran

*Corresponding author: Ehsan Shahverdi, Iranian Blood Transfusion Organization building, Hemmat express way Tehran, Iran, Tel: 982188601606; E-mail: shahverdi_ehsan@yahoo.com

Received Date: December 03, 2016, Accepted Date: December 04, 2016, Published date: December 15, 2016

Copyright: (c) 2016 Shahverdi E, et al. This is an open-access article distributed under the terms of the Creative Commons Attribution License, which permits unrestricted use, distribution, and reproduction in any medium, provided the original author and source are credited.

Citation: Shahverdi E, Khani MA (2016) Pain Management after Surgery. J Pain Manage Med 2: e105.

\section{Editorial}

Acute pain following surgery known as the issue that most patients suffer from it; but chronic pain after surgery is a problem that has needed a little more attention. Depending on the type of surgery, $10 \%$ to $68 \%$ of surgical patients may be suffering from chronic pain that $2 \%$ to $10 \%$ of them suffer from severe pain [1]. There is no exact definition of chronic pain after surgery, and also differences in diagnostic procedures and questionnaires used for evaluation of pain after surgery, may explain the differences in prevalence rate in various studies. Currently it is accepted that duration of pain after surgery should be lasting at least two months after the operation time to make a trustworthy diagnosis [2]. Risk factors of chronic pain after surgery divided into three periods: before surgery, during surgery and after surgery.

Pathophysiological processes that occur after tissue damage indicate that acute pain may become persistent. Inflammation at the site of tissue damage creates a barrage of afferent nociceptors activity that causes peripheral and central nervous system sensitization and creates functional changes in the peripheral nerves, spinal cord, higher routes pain center and the sympathetic nervous system $[1,3]$. It seems that specific receptor sites such as N-methyl-D-aspartate receptor is particularly important in chronic pain following acute injury and descending pathways pain control also probably the decisive factor in chronic pain [3]. In another systematic review it has been shown that administration of Gabapentin consumption before surgery cause more reduced pain after surgery compared to the control group and also may decrease the dose of opioids and side effects [4]. Chronic pain after surgery often has a neuropathic component. Even in the early stages, it can be seen as a neuropathic pain after surgery [3,5]. Therefore, drugs for treatment of chronic neuropathic pain are used as the adjuvant drug for pain ante surgery increasingly.
It has been shown in numerous studies that some drugs such as Gabapentin and Pregabalin, not only can reduce the severity of acute pain after surgery and reduce the analgesic dose but also may contribute to the prevention of chronic pain after surgery. In a metaanalysis of Clark and colleagues, it was found that the use of Gabapentin and Pregabalin improved the patient functional outcomes in long-term [6].

Various mechanisms have been suggested for these drugs, but it is still not entirely clear that what extent involve these mechanisms the analgesic effects of this drug, dose, metabolism and drug interactions, but now evidence-based data revealed that there is no report of the duration of optimum consumption time and need for further investigation.

\section{References}

1. Miller R (2004) Miiier's Anesthesia Philadelphia: Churchill Livingstone.

2. Buvanendran A (2012) Chronic postsurgical pain: are we closer to understanding the puzzle? Anesth Analg 115: 231-232.

3. Macintyre PE, Scott D, Schug S, Visser E, Walker S (2010) Acute pain management: scientific evidence. Aufl ANZCA \& FPM, Melbourne.

4. Tiippana EM, Hamunen K, Kontinen VK, Kalso E (2007) Do surgical patients benefit from perioperative gabapentin/pregabalin? A systematic review of efficacy and safety. Anesth Analg 104: 1545-1556.

5. Ramaswamy S, Wilson JA, Colvin L (2013) Non-opioid-based adjuvant analgesia in perioperative care. Contin Educ Anaesth Crit Care Pain 13: 152-157.

6. Clarke H, Bonin RP, Orser BA, Englesakis M, Wijeysundera DN, et al. (2012) The prevention of chronic postsurgical pain using gabapentin and pregabalin: a combined systematic review and meta-analysis. Anesth Analg 115: 428-442. 